\title{
Overseas Training For Specialist Registrars
}

$\mathrm{T}$ Lowes

\section{Introduction}

This article is designed to provide guidance for those specialist registrars who wish to undertake part of their training overseas.

Working in a hospital abroad was an accepted part of military medical training in the days when there were British M ilitary $\mathrm{H}$ ospitals in many locations around the world. D espite the closure of these hospitals, the wish to travel and gain experience unavailable in the N HS, has seen many Specialist Registrars (SpRs) continue the tradition of working overseas.

\section{Timing}

This will depend principally on the guidelines of the particular College and also on the speciality Defence Consultant Adviser (DCA). Work overseas can be classed as 'outof-programme experience', in which case it will be in addition to the required 5 or 6 years of $\mathrm{SpR}$ training. However, given the current shortage of military consultants, anything that extends the time needed to achieve the Certificate of Completion of Specialist Training (CCST) may not be looked upon favourably. $\mathrm{H}$ aving training approved as part of one's SpR programme may be preferable. As an example, the Royal College of Anaesthetists allows one year of SpR training to be overseas, as long as certain guidelines are followed (See Approval for Training below). This would generally be during the fourth year of $\mathrm{SpR}$ training. The penultimate year of training (year 5 ) is advised for surgeons.

It will also be necessary to negotiate with the

Maj T Lowes M BBS

FRCA Dip

IMC RCS(Ed) RAM C

Specialist Registrar in

Anaesthesia and

Intensive $\mathrm{C}$ are

Royal Adelaide

H ospital, Adelaide,

South Australia 5000,

Australia

Email: tlowes@doctors.org.uk

Surg Lt C dr R M $\mathrm{H}$ eames M BBS FRCA

RN

Specialist Registrar in

Anaesthesia

Vancouver G eneral

H ospital, Vancouver,

British Columbia

V5Z 4E 3,C anada plan for this at least eighteen
the intended departure date.

\section{Hospital and Location}

$H$ aving taken the decision to uproot and move to another country for a year there are two further decisions that must be made: which country and which hospital?

For most, the choice of country will be limited by the need for somewhere Englishspeaking and where training is recognised by the respective UK Royal Colleges. The most commonly chosen are: USA, Canada, Australia/N ew Zealand and South Africa.

$M$ any choose a hospital where predecessors have worked and recommended the post. This should make both arranging the year and

justifying the request to the Army rather easier. M ost of the Colleges have information on hospitals abroad where other trainees have worked. In addition, many hospitals now have websites that provide specific information on Fellowships for overseas doctors.

Generally, to ensure senior agreement and military funding for the year, the training should be militarily relevant and not available in the UK. For surgeons this may mean trauma surgery in the USA or South Africa and for anaesthetists possibly trauma anaesthesia or aeromedical retrieval in one of the countries listed above. These are perhaps the more obvious examples, however with reasonable justification, a variety of posts have been accepted in the past.

\section{Applying for a post}

It is essential to speak to the DCA and agree the country, hospital and position being applied for. If they are not in agreement with the choice there is no point in going any further with the application. If agreement is forthcoming, a formal application for the post can then be sent to the hospital in question. An important point which will assist the application is the fact that, subject to approval, salary costs will be paid by the Army during the attachment.

When a formal job offer has been made, it is necessary to inform the hospital that approval from both the Army and the Royal College will be necessary before formal acceptance is possible.

\section{Approval for Training \\ Defence Consultant Adviser}

There is a formal chain of approval that must be followed, starting with the DCA, as described above.

\section{Royal College}

The Colleges have guidance for approval of overseas training if it is to be counted towards one's CCST. In general this requires a letter to the College that includes the following:

- $\mathrm{N}$ ame and location of $\mathrm{H}$ ospital.

- Head of D epartment.

- $\mathrm{N}$ ame of Supervisor.

- Confirmation that the College of the country recognises the post for training.

- Description of the post including information on proposed research.

- Aims/objectives of the year.

- A letter of support from the DCA. 
Defence Postgraduate Dean

A letter of justification for the chosen post must be sent by the DCA, along with a letter confirming College agreement, to the $D$ efence Postgraduate D ean.

\section{Army Medical Directorate (AMD)}

Currently, Medical Officers in training positions overseas are posted to AMD as 'held strength'. Things may change in the future so that the Defence $M$ edical Education and Training Authority (DMETA) take over this role from AMD. Until then, the AMD Budget Holder must approve travel and subsistence for the move to a new post. AMD will also obtain authority to fund salary costs during the year abroad.

Other costs and allowances/entitlements associated with a year overseas continue to be an issue. There are ongoing discussions regarding funding, which may not be resolved for some time. U nlike L oan Service and Exchange Officer posts, there are no written procedures or financial authorities for hospital attachments/ fellowships overseas. This procedural deficiency may continue to cause administrative difficulties until it is remedied. So far, administration staff have managed to ensure that medical officers have not been disadvantaged financially, and hopefully this will continue.

\section{NHS SpR Programme Director}

If planning to return to the same Region to complete SpR training, it will be necessary to inform the local Programme Director of this intention and ensure their approval to rejoin the training programme afterwards. These plans may also come up for discussion at a Record of In-Training Assessment (RITA) interview; however no formal 'approval' is required.

\section{Administration British Defence Liaison Staff}

Invariably, one of the main sources of information from now onwards will be a member of the British D efence L iaison Staff (BDLS), often a Staff Sergeant or Warrant Officer, based in the British $\mathrm{H}$ igh Commission or Embassy of the country concerned (in some countries this is a Triservice post). As soon as the posting has been approved, the U nit Admin Office (UAO) at AMD will seek BDLS assistance to manage pay and personal administration in country. BDLS staff have always proved very helpful and should one wish to contact them,

the UAO at AMD will be able to provide e-mail/telephone details). With BDLS help, AMD will prepare an information pack containing information on travel, accommodation, driving, medical, visas, baggage/customs requirements, pay/ allowances etc.
Mail

One option is to have all mail redirected to the overseas address by the Royal $M$ ail (around $f 70$ for the year), which avoids the hassle of writing 'change of address' letters to multiple people and institutions, not to mention the additional cost journals charge for overseas postage. It may be worth reminding some people that letters sent from the UK require additional postage; a first class franked letter may otherwise take up to 3 months to arrive by sea!

\section{Visas}

Requirements differ depending on the country. BDLS may state that a visa is not required and travel should be on a NATO Travel Order. This is fine if the attachment is to a military unit. U nfortunately, as a doctor applying for registration with a civilian regional/state health authority, the lack of a visa can cause significant problems. For this reason many trainees apply for an Occupational Training Visa as any other trainee would. It is vital to be aware though, that the privileges certain countries apply to servants of the Queen with regards to spouses being permitted to work overseas (see F amily below) will then not apply.

Visa application forms can often be downloaded from the website of the respective embassies in L ondon. A chest X-ray may be required from a registered (private) radiologist and possibly a medical examination too. Approval for this should be obtained from AM D.

It will be necessary to send off your own (and accompanying dependants') passport(s). This whole process may take up to three months (although it is usually quicker and time can be saved by taking the application to the embassy in person).

\section{Flights}

The D efence Passenger Reservation Centre (DPRC) is responsible for arranging flights. Once authority has been received from AM D and suitable dates have been agreed, the DPRC should be contacted (020 7218 1472). The cheapest scheduled flight is generally booked (i.e. not British Airways), however, for flights further than NW Europe DPRC will book business class tickets and even young children will have their own seat and luggage allowance. For small children/babies it is worth asking the airline for permission to fit one's own car seat in the plane (certain standards/restrictions apply) as children may travel better in something familiar/ comfortable and it won't be necessary to have them sitting on an adult's knee as much.

DPRC staff are helpful and will arrange dates and times as close to requirements as possible. Depending on the flight time, the option of a stopover is available with some destinations (e.g. Singapore/K uala Lumpur for A ustralia/NZ). H otel accommodation and 
subsistence allowance for one night is permissible if flying with children. AMD will book this in advance.

\section{Pre/Post E mbarkation Leave}

The whole process of moving to another country takes time. The entitlement is10 working days ( 2 weeks) between theatres for a one-year overseas posting (Army Leave $\mathrm{M}$ anual, Chapter 2, paragraph 0223).

\section{Baggage \\ Accompanied Baggage}

The weight allowance per person for international business class flights is usually around $40 \mathrm{~kg}$. A family of four will probably struggle to carry this amount of luggage. Clothing and other personal effects required during the first two weeks are needed. M edical certificates, confirmation of job offers, references etc. should be carried in hand luggage for safety.

\section{Unaccompanied Baggage}

The QM's department at AMD will send information regarding unaccompanied baggage, including The Joint Services U naccompanied Baggage Guide (F/M ov/713). M ost importantly, this includes a list of prohibited items which includes furniture. Some countries may exclude all wooden items and require declaration of items that may be contaminated with soil. Bicycles are acceptable if wheels/pedals are removed and handlebars rotated. If it fits in a $1 \mathrm{~m} 3$ box, it should be allowable.

U naccompanied baggage is routinely sent as air-freight and takes around 4 weeks to arrive after removal. T he allowance varies depending on rank, marital status and number of children (for example $M$ arried and accompanied with 1 child $=10.78 \mathrm{~m} 3(1935 \mathrm{~kg})$

After receiving a completed $\mathrm{F} / \mathrm{M}$ ov/713A, the $Q M$ will notify $M \& S$ shipping who will then make contact to arrange a date for a Surveyor to visit. This can be 4-6 weeks prior to departure. The company will usually remove baggage 2-4 weeks before departure.

C ustoms Forms need to be completed and copied. In some countries it will be necessary to clear your own baggage on arrival; in others and subject to agreement, BDLS staff may arrange clearance and delivery. If they do, they will require copies of the $C$ ustoms F orms and passports.

\section{Storage}

White goods and furniture, (and anything else not required during the time abroad) will need to go into storage (unless renting out the property). Again, a form needs to be completed and returned to the $\mathrm{QM}$ and a date for surveyor (different company) arranged. Removal of these items should be arranged for the last working day before departure, as the entitlement is only to a couple of days in a hotel prior to leaving.

\section{Cars}

There are 3 main options:

1. Selling before departure means available cash to buy a car abroad. U nfortunately buying and selling costs, in both time and money. Timing the sale to coincide with departure is also very difficult (without giving away money to dealers), and friends/relatives may need to assist.

2. Storing the car may be free in a relative's garage but insurance, depreciation and problems after a year of lying idle need to be considered.

3. Signing ownership over to a trusted relative (for insurance purposes) may be the best compromise. If they appreciate the extra car for free, they may take care of insurance and maintenance costs, although depreciation remains.

\section{Insurance}

Reasonable insurance for items in storage may be provided by the storage firm up to a certain amount and with exclusion of such items as antiques or valuable paintings

It is mandatory to arrange insurance for both accompanied and unaccompanied baggage. In addition insurance will be required for all of these items plus any others rented or bought during the time abroad (this may includeT V, DVD, white goods and other similar items). One option is the K itcare Essentials package provided by JBI International $(0118 \quad 9810222$ or www.jbidirect.co.uk), which covers everything for the year.

\section{Accommodation \\ Transit Accommodation}

If living in married quarters it will be necessary to arrange inspection and handover dates with the local $D$ efence $H$ ousing $O$ fficer. AM D are able to book hotel accommodation for up to 3 days prior to departure. Whilst the cheapest option will always be chosen, AM D can arrange a hire car for transfer to the airport.

If it is not possible to move immediately into furnished accommodation on arrival, prior permission can be obtained to stay in an hotel (an apartment is easier for those with children) for a limited period. AMD will arrange this or indicate the maximum nightly rate payable so that it can be booked independently and claimed back on the usual Form AF 01771.

\section{Permanent Accommodation}

For the vast majority of locations, M ilitary accommodation will not be available. AM D will be able to obtain the current rental allowance for the country of attachment. Entitlement is for the equivalent accommodation that would be provided at home (for example major - 4 bedroom plus garage). In certain parts of the country the allowance may cover significantly better 
accommodation than in others (for example Adelaide vs. Sydney). The standard deductions for a married quarter in the UK will appear on one's monthly pay statement.

It is a personal responsibility to find appropriate accommodation within the given price range. Staff at the local hospital should be able to offer suggestions regarding the best areas to live in and details such as local amenities and public transport. Local newspapers and estate agents often have websites which can be searched a month or two before departure. Alternatively, accommodation may be advertised through the hospital or local university. It may even be possible to take over the home of the previous Fellow/Visiting doctor.

Arranging accommodation before arrival saves much time and stress. If it is possible to persuade someone to look at properties on one's behalf before departure, a provisional rental agreement may be in place before departing the U K.

\section{Furnished/Unfurnished}

Renting fully furnished is by far the easier and preferred option. If there is no fully furnished property available, it may be possible to furnish rented accommodation with the assistance of the $O$ verseas $F$ urniture Provision Scheme (OFPS). This is considerably more expensive for the Army and AMD would definitely have to authorise this. White goods should be provided in furnished accommodation and audiovisual equipment can be either sent by airfreight or purchased/rented on arrival.

\section{Utilities}

Estate agents should be able to assist with connection of gas, electricity, water and telephone. For communication with friends and family at home a broadband connection is well worth the additional cost. M ost countries have various discount phone vouchers that can be purchased from newsagents. These allow telephone calls to the UK at a fraction of the standard charge. A mobile phone may also be invaluable.

\section{Administration Visit to BDLS}

At some stage during the first week or two in country a visit should be made to the British $\mathrm{H}$ igh Commission. This provides an opportunity to meet the Staff Assistant with whom one has been corresponding, allows a detailed in-country briefing and is an opportunity to deal with important paperwork. If it has been agreed in advance, it is also the opportunity to hand in travel and accommodation claims.

\section{Finances}

\section{Banking Arrangements}

Some international banks have branches in London and it may be possible to open an account before departure (the process may take several weeks, so it should be done early).

This is one less thing to do after arriving and also means that account details can be provided for direct debit payments such as house rental and utilities.

\section{Pay}

If arranged in advance it may be possible to cash a cheque with BDLS (up to one months net pay), and in addition to ask for a month's advance of pay. This can be useful for buying a car shortly after arriving. It is also useful to complete a $\mathrm{M}$ ain Pay Allotment form so that a fixed amount of each month's salary is paid into the new bank account (remembering to leave enough money in the account at home to cover monthly direct debit payments such as credit cards). Alternatively pay arrangements may be left as they are, with reliance on credit cards or monthly cheque encashment.

\section{Credit Cards}

Companies will be reluctant to issue credit cards to persons who are only temporary residents. A letter of reference from BDLS may sometimes assist. For the financially astute, use of a UK credit card will depend on the difference between the current bank exchange rate and the Forces Fixed Rate of Exchange (remembering that in addition, banks and credit card companies will always include an 'administration' percentage within their exchange rates for transactions abroad).

\section{Forces Fixed Rate of Exchange}

This is set for 3 months at a time and is used to calculate the exchange rate for pay Allotment or cheque encashment. AM D will know the current rates.

\section{Driving}

Depending on the Country/State, it may be possible to drive for a year using a UK D riving Licence or with an International Driving Licence (available from main Post Offices). Some countries may accept this for the first 6 months and then require all or part of the local D riving Test to be taken (BDLS can advise).

The purchase of a car is an individual choice and the issues are those of second-hand car sales in any location. It is worth asking one's insurer in the UK for confirmation of noclaims status which may then be taken into account by overseas insurers.

\section{Work \\ Medical Registration}

Doctors must register with the local State/N ational M edical Board/C ouncil before they are permitted to practice. The hospital should provide the necessary information and a list of requirements. These usually include:

- Certificate of G ood Standing (free from GM C). 
- Certificate of original M edical D egree -

- Confirmation of your position at the local hospital.

- Reference(s).

- Visa and passport.

- Passport photos.

- M oney (to pay the registration fee).

\section{Medical Indemnity}

It is possible that either the M DU or M PS (or similar body) in the UK may have an agreement with overseas medical indemnity agents for no extra fee, however, this may have to be arranged.

\section{Hospital}

The usual tasks when starting work at a new hospital include:

- Rota and leave arrangements.

- M edical administration (honorary contract etc.).

- Occupational health (copies of H ep B and other vaccinations).

- Pager and ID cards.

- Lockers, door codes and computer passwords.

\section{Medical/Dental Care \\ Medical}

Any essential medical care (including family care) during the visit will be paid for by the Army. BDLS will advise if it is necessary to register with a healthcare scheme (e.g. Medicare in Australia). It is important to register with a local M edical Practice.

\section{Dental}

Full dental fitness (including the family) must be in place prior to travelling overseas. Routine (annual inspection) and emergency dental treatment can be claimed back in full (including children under 16). Spouses are entitled to a partial refund (less normal N HS charges - unless pregnancy rules apply). A routine visit must not be within the first or last 3 months. (See DCI (JS) 63/03).

\section{Family}

\section{Employment of Spouse}

Advice should be sought from BDLS. Spouses should be allowed to work on the basis of a $\mathrm{N}$ ato travel order. If travelling on a training visa, spouses would then have to apply for their own working visa prior to leaving the UK.

\section{Schools}

Schooling arrangements for accompanying children should be made before leaving the UK. Children are entitled to an equivalent education to that which would be expected in the UK. BDLS and local hospital staff can advise.

\section{Allowances}

The following may be claimed:

- L ocal O verseasAllowance(AM D or BDLS staff may advise e.g. $M$ ajor married and accompanied, one child - $£ 22.57 /$ day).

- Residence to Place of D uty

\section{Returning Home Posting Order}

A Posting Order for the next place of work is essential for most of the paperwork required for returning home.

\section{Flights}

AMD will arrange these or will approach BDLS for help in arranging them, with the same guidelines applying as on the way out. Alternatively it is possible to request permission to utilize the MOD Privately Arranged Passage (PAP) scheme. In essence one arranges one's own travel home and then reclaims costs up to the value of business class travel on the standard route. This might enable a 'round the world' ticket or cruise home.

\section{Baggage}

Arrangements are similar to those on the way out. For U naccompanied baggage there is an option to claim the equivalent cost and arrange shipping by sea so that many larger items can be taken home. Recent communications have, however, reminded personnel that this should not include the transport of motor vehicles; these must be shipped at your own cost.

\section{Accommodation}

If hotel/apartment accommodation is required prior to departure, financial authority should be obtained from AMD. Six nights may be allowed.

Application forms for military/rental accommodation at the next place of duty should be requested from AMD, although BDLS may have them. There is also a form for arranging removal of belongings from store.

If not returning to fully furnished accommodation, it is possible to request hotel accommodation close to the new duty station for 3 days.

\section{Cars}

There is no entitlement to a hire car prior to leaving unless the alternative cost of a taxi to the airport would be excessive.

On arrival in the UK a hire car may be arranged for transport from the airport to the new Duty Station only (i.e. 24hrs hire maximum). Again AM D financial authority is needed for these.

\section{Miscellaneous}

It is vital, amongst other things, to remember to:

- Terminate rental agreements. 
- Close bank accounts.

- Redirect mail.

- Finalise utility payments.

- Rearrange schools.

\section{Medical Reports and assessments}

Prior to leaving a summary of training and an assessment/report is required from the nominated Educational Supervisor. This will be required for the next RITA and OJAR. In addition to this, each Trainee is required to write a report of the year for their Royal College and D efence Adviser.

\section{Summary}

A year overseas is an option that should be seriously considered by any M ilitary Specialist Registrar. It is a great chance to experience life in another country outside an operational deployment (accompanied by family). Excellent opportunities for training now exist in perhaps more locations around the world than were ever available before.

There are many things to consider when arranging overseas training and these are detailed within this article. Expected changes in the role of AM D and DMETA with regards to SpR s may alter some of the administrative responsibilities described. Funding is an ongoing issue and hopefully this will be clarified with written procedures and agreed financial authorities in the future.

The experience gained will be well worth the effort involved in planning and organisation. Trainees should make the most of this opportunity while they are able to. 